\title{
Feasibility of Laparoscopic Surgery for Intussusception in Pediatric Patients and Risk of Bowel Resection
}

\author{
Hye Kyung Chang, M.D., Ph.D. \\ Division of Pediatric Surgery, Department of Surgery, Kyung Hee University Hospital, Kyung Hee University College of Medicine, Seoul, Korea
}

\author{
Corresponding author \\ Hye Kyung Chang \\ Division of Pediatric Surgery, Department of Surgery, Kyung Hee University Hospital, 23 Kyungheedae-ro, Dongdaemun-gu, Seoul 02447, Korea \\ Tel: +82-2-958-9506, Fax: +82-2-958-9507, E-mail: hkchang@khu.ac.kr \\ ORCID: http://orcid.org/0000-0003-2537-7464
}

This is an Open Access article distributed under the terms of the Creative Commons Attribution Non-Commercial License (http:// creativecommons.org/licenses/by-nc/4.0/) which permits unrestricted non-commercial use, distribution, and reproduction in any medium, provided the original work is properly cited.
Copyright $@ 2018$ The Journal of Minimally Invasive Surgery. All rights reserved.
Minimally invasive surgery is believed to be the mainstream of treatment in many surgical procedures on children with successful outcomes. Despite the advantage of laparoscopy over laparotomy, laparotomy was the treatment of choice for the management of radiologically irreducible intussusception in children until a few years ago, with laparoscopic reduction of intussusception as an alternative treatment option to a laparotomy. ${ }^{1,2}$ As the laparoscopic technique is advanced with the accumulated experience of laparoscopic management of intussusception in children, laparoscopy has been recommended as the primary choice of treatment for intussusception in children in recent studies. ${ }^{3,4}$

Laparoscopic management of intussusception is a challenging procedure. First of all, it is difficult to make a pneumoperitoneum for sufficient space to move the laparoscopic instruments in a small child with marked abdominal distension. The laparoscopic procedure is difficult to perform in the limited peritoneal space with a distended bowel. The intussuscipien is difficult to find laparoscopically because of the distended proximal intestine over it. In addition, the reduction is not easy if the intussusceptum has impacted severely. During the laparoscopic reduction of intussusceptum, injury to the bowel can occur as serosal tearing or even perforation. In early reports of laparoscopic treatment of intussusception in children, the success rate of laparoscopy was only 65.3\% in 98 children. ${ }^{5}$ In a multicenter retrospective study, the risk factors for conversion to open surgery were the long duration of the symptoms, presence of signs of peritonitis, and presence of a pathologic lead point. ${ }^{6}$

The authors have an excellent success rate of laparoscopy (78.4\%) for the reduction of intussusception with a relatively large number of cases $(n=37)$. This success rate of laparoscopy is comparable to other recent studies with good results. ${ }^{4,7}$ Laparoscopic treatment of intussusception in children is technically feasible with successful outcomes if the patient shows no signs of peritonitis or severely distended abdomen. Although the pathologic lead point can make the reduction impossible, the need for bowel resection with conversion to open surgery can be decided according to the presence of a lead point or the failure of reduction after a laparoscopic trial of reduction of intussusceptum. Laparoscopy should be considered as a treatment of choice on a child with intussusception after a failed radiologically reduction.

\section{REFERENCES}

1) Burjonrappa SC. Laparoscopic reduction of intussusception: an evolving therapeutic option. JSLS 2007;11:235-237. 
2) Sklar CM, Chan E, Nasr A. Laparoscopic versus open reduction of intussusception in children: a retrospective review and metaanalysis. J Laparoendosc Adv Surg Tech A 2014;24:518-522.

3) Apelt N, Featherstone N, Giuliani S. Laparoscopic treatment of intussusception in children: a systematic review. J Pediatr Surg 2013;48:1789-1793.

4) Wei CH, Fu YW, Wang NL, Du YC, Sheu JC. Laparoscopy versus open surgery for idiopathic intussusception in children. Surg Endosc 2015;29:668-672.

5) Poddoubnyi IV, Dronov AF, Blinnikov OI, Smirnov AN, Daren- kov IA, Dedov KA. Laparoscopy in the treatment of intussusception in children. J Pediatr Surg 1998;33:1194-1197.

6) Bonnard A, Demarche M, Dimitriu C, et al. Indications for laparoscopy in the management of intussusception: A multicenter retrospective study conducted by the French Study Group for Pediatric Laparoscopy (GECI). J Pediatr Surg 2008;43:1249-1253.

7) Houben $\mathrm{CH}$, Feng $\mathrm{XN}$, Tang $\mathrm{SH}$, Chan EK, Lee KH. What is the role of laparoscopic surgery in intussusception? ANZ J Surg 2016; $86: 504-508$. 